\title{
The Absence of Longer Texts in Literature Classes in Some Open and Distance Education Courses in India: Learning Outcomes
}

\author{
Chatterjee, Arnab ${ }^{1}$ \\ ${ }^{1}$ Ex-Senior Research Fellow, (University Grants Commission, New Delhi), Department of English \& Culture \\ Studies, The University of Burdwan, West Bengal, India and Assistant Secretary (Honorary), Poets Foundation, \\ Kolkata, India \\ Correspondence: Chatterjee, Arnab, "Rupa Villa", 1/G Sashi Bhuson Ghosh $1^{\text {st }}$ Bye Lane, Post Office: Mahesh, \\ City: Serampore (near Calcutta/Kolkata), Pin/Zip Code: 712202, District: Hooghly, State/Province: West Bengal, \\ India. E-mail: arnabserampore2011@gmail.com
}

Received: May 21, 2018; Accepted: June 1, 2018; Published: June 24, 2018

\begin{abstract}
Self-Instructional Materials (SIMs) in distance and open learning (ODL), particularly in case of literature modules in certain open universities in India do not seem to provide the longer texts of works penned by both canonical as well as non-canonical authors; short poetry and critical pieces are just some of the exceptions. Often the emphasis is on the critical material available on the author, coupled with notes and commentaries. As any understanding of a text is important to gain a deeper understanding of the socio-economic and the cultural milieu in which the work was conceived, while "reading between the lines" can be of additional help, often this absence raises questions as regards the efficiency of the SIMs used in the literature classroom. On the other hand, regular courses in the nation emphasize the reading of the text per se. This paper would like to analyze the learning outcomes of around fifty students in the ODL mode and around the same number of students in a literature class in "regular" mode using the theories of learning and behavioral conditioning in psychology and analyze this issue of availability and nonavailability of texts in a classroom, particularly in a literature course from the vantage point of student responses and subsequent evaluation in exams.
\end{abstract}

Keywords: ODL, Regular, Literature, SIMs, Module

\section{Introduction}

Considerable difference exists in pedagogical formats when it comes to the enunciation of the teaching methodology in ODL (open and distance learning) modes of learning and regular/non-ODL modes; yet the former is a viable means of supporting the attainment of [higher] educational, social and economic parameters (Mnyanyi and Mbwette 1; Mohanachandran and Ramalu 198; in Musingafi et al. 59). While the ODL mode does not believe in "artificial" differentiation when it comes to the choosing of learners and believes that a genuine inclination towards knowledge is what one needs to enroll in such courses of study (Note 1), "regular" courses are wide apart from such a philosophy of learning and set bench mark in form of cut off percentile, entrance exams and the like. Regular modes of study, especially in a nation like India (and in other nations as well) rely on a core 'syllabus', the same that has to be 'covered' or completed by a discerning teacher within a stipulated period of time - often, the thrust is on the teacher and not the learner. There is thus, an alternative means to this curriculum of study that is christened by Open and Distance Learning (ODL). ODL modes rely on a subject counselor who discusses a specific topic during a class within a credit system and the thrust is often on the learner within a learner-centric matrix. Use of SIMs or self-instructional materials, coupled with home assignments that would enable the learner to read the material is often the pedagogical thrust in such cases. A portion of marks earned in such home assignments is then transferred to the marks that the student earns in the exam. Student support services often embrace systems as diverse as technology, remedial teaching, non-compulsory PCPs (or personal contact programs) and GD. In this connection, it has been rightly pointed out:

The main task of any ODL provider is to design and offer open distance educational experience that encourages learning interactions which affects the learner's success in ODL.

Interaction in the conventional classroom or lecture room is much different than the interaction that occurs in Open Distance Learning. Learning interaction is fundamental to ODL because study completion success is dependent 
on how effective the students are interacting with the course content, tutors and with their peers in their learning. (Dzakiria 1)

In many ODL classes, learners are often seen not to be in sufficient touch with their compeers in India simply because of the fact that they do not 'know' each other due to the non-compulsory attendance of classes as against in a regular mode wherein classes need to be compulsorily attended and a percentage maintained. Yet this phenomenon of being not in contact with the teacher in contact programs has not directly influenced the academic achievement in end semester results, as against them who have been in contact, as per a study conducted by Fritsch and Strohlein in 1988 (in Olivier 77). This paper would like to stress such problems that is often encountered in ODL modes of study in the Indian subcontinent with respect to some Open universities and the literature classes in an MA course where texts are often absent. The thrust is often on the critical commentary and a summary of the entire text coupled with some smattering of "probable" questions here and there. This emphasis on "probable questions" often gives the students the necessary impetus to enroll in a course and get the desired marks for the job market and the ODL mode is seen by many (if not by all) to be a viable means to earning of a degree and thereby getting promotion in places wherein they already are employed for years at a stretch. This is the trend that may often, if not always, be seen in some ODL modes of study in India vis-à-vis student expectations from the same.

\section{The Aim of the Paper/ The Problem}

The aim of the present paper is to compare a group (around 50 students) from both a literature class in a Master degree program India from a regular mode and a corresponding sample of population from an ODL mode and see how learning outcomes are affected/facilitated by the presence and absence of texts of a canonical writer like Franz Kafka (1883-1924), the Czech writer and one of the early exponents of Absurdist literature and determine how such a parameter would determine learning outcomes. It would, inter alia, look at other determining factors in a class in both these modes of study such as peer interaction, the use of ICT (if any), assignments given and the like and the effect that they may have on learning outcomes.

\section{The Sample of Population Addressed}

Both the modes of postgraduate study embracing European literature of the $19^{\text {th }}$ and $20^{\text {th }}$ centuries had around 55 students. However, while the regular mode had students within the age group of 20-22 ( $N=19.7)$, the ODL mode had a much more pronounced difference between the ages, with some learners within the former age group to many learners of around $40(\mathrm{~N}=23)$. Both the modes of study had students coming from diverse backgrounds; both had learners from rural as well as urban areas as well as learners from very well-to-do families and from extremely financially underprivileged ones. The number of females predominated the males in both the groups. For the purposes of this essay, both the groups would be designated A and B respectively_ "A" for the group enrolled in regular mode of study, and "B" the one enrolled in the ODL mode. The students in both the groups were selected by a cut off percentile of marks, though for A, it was around $55 \%$ in the preceding examination, while for B, it was $40 \%$.

\section{Theoretical Underpinnings}

It has to be understood that in the Indian context (on which the present study is based), that scoring well in the term-end examination is often considered the goal of attending classes and studying and that there seems to be a positive correlation between the two (Narula and Nagar 207). (Note 2) Therefore, the effect of removing/absence of a canonical text in class and the nature of the term/semester end results in both ODL and regular modes and the motivation that the learners gain thereof may help situate the whole paper from the point of view of B.F. Skinner's theory of operant conditioning in the context of a learner-centric curriculum. Skinner's theory of conditioning and his famous use of the "Skinner Box" used the concept of stimulus and response- that is, some of positive behaviors would be learnt when there is what is called reinforcement-desired actions that were essential for conditioning of a response. In some learning situations, the animal/human fails to make correct responses. In that case, the behavior that is considered closest to the correct is made to be reinforced, and that is what Skinner called "shaping". Skinner was not concerned with what went inside the organism per se; he was more attuned to the fact that a complex array of factors influence learning, as "[E]ndogenous factors have largely been considered private, inaccessible and in some cases, hypothetical... (in Thompson 423). Thus, according to the operant conditioning theory, UST---URE---PRE- $\rightarrow$ CRE, where, UST: Stimulus; URE: Response; PRE: Action/Response. If PRE is sufficiently recorded/received, then it is said that the learner's CRE is a conditioned response. Thus, whether being deprived of a text in a class (that is often seen as a prime component in a literature class and a useful parameter of the understanding/appreciation of module) has actually anything to do with learner satisfaction/dissatisfaction is 
what would be analyzed, even though Skinner opined that "the relevant variables of deprivation and satiation [and] must face all the complexity of these operations" (qtd. in Wolman 136).

Thus, in both the groups, what would be focused is whether the presence/absence of a text/s vis-à-vis positive learning outcomes generated from term-end examinations does in any way take a text into consideration as one of the prime, extraneous factors in enhancing understanding about the module that is taken to be a unit of analysis in the term end examination or not. The paper would radically probe into the question if the presence/absence of a literature text in a postgraduate classroom does in any way impede learning and learner satisfaction, the latter that is often seen to be the function of the nature of the results in term end exams. Thus, whether the presence/absence of a text in the class (or the factor of "avoidance" and "escape" in Operant Conditioning) positively reinforces learning and its outcomes, and to what degree is what is the avowed aim of the paper.

\section{Methods/Tools}

The main tools that were used were Questionnaires, Interviews and Group Discussions after a particular module was finished. The learners of both the groups were asked after their term-end exams about the desirability of a text in the class and to what extent did it contribute to their success/failure in term end exams. Students of both the groups were given printed questions, were interviewed in "activity" classes on this and even split into groups comprising of around 25 each during the GD.

\section{Getting Started}

In the first group, i.e., Group A, there were around 50 students and the number of females exceeded that of the males. The text under consideration was the novel The Trial (1925) by the noted Czech writer Franz Kafka. The class was first acquainted with the milieu in which Kafka was writing and students were told about the other major texts of the writer and how he is considered a prime, early exponent of the Absurd literature. A text published by the Penguin edition was chosen and students were told to pay particular attention to it. However, during the course of administering this module under "European Literature", it was found that students were more focused towards surrounding other general information surrounding Kafka and not on the text per se. Except 5 students, most of the class was without the text of the novel. After the text had been discussed, students were asked the reason for their non-appreciation of the same through individual interaction and questionnaires in the next class that was specifically reserved for this, though in a regular mode of study, the focus if often on the completion of the syllabus and not on such 'issues':

Reasons for the absence of the text of The Trial in the class and learning outcomes:

1. Did you attend the first class in European literature wherein it was told to bring the text in the class? $\mathrm{Y} / \mathrm{N}$

2. Did you find the Penguin edition easily? $\mathrm{Y} / \mathrm{N}$

3. Did you find it costly? $\mathrm{Y} / \mathrm{N}$

4. Did you find an online edition? $\mathrm{Y} / \mathrm{N}$

5. Did you find a second hand edition? $\quad \mathrm{Y} / \mathrm{N}$

6. Was the fact that as answering an extract from novels is optional, the text was not given attention? $\mathrm{Y} / \mathrm{N}$

7. Do you feel that the text was destined to be a big bore? $\mathrm{Y} / \mathrm{N}$

8. Do you feel that a summary is more than enough? $\mathrm{Y} / \mathrm{N}$

9. Do help books available in the market that do not incorporate the text help in exams? $\mathrm{Y} / \mathrm{N}$

10. You feel there is no need for a text? Y/N

11. Does the fact that being without a text may deprive you of the class attendance for that day provide some incentive to bring the text? $\quad \mathrm{Y} / \mathrm{N}$

Sheet 1 .

Students were administered the given questionnaire and were split into two groups to facilitate a Group Discussion (GD) that would help them gather peer opinions and then mark a "Y/N" to a question. The time that was allotted 
was 15 minutes per group for both the GD as well as for answering the questionnaire. The responses were recorded on a spread sheet that gave the following data:

Table 2.

\begin{tabular}{lllll}
\hline Question no. & 15 students & 14 students & 14 students & 7 students \\
\hline 1 & Y & Y & Y & Y \\
2 & Y & N & Y & Y \\
3 & Y & Y & Y & N \\
4 & N & N & Y & Y \\
5 & N & Y & Y & N \\
6 & Y & Y & Y & Y \\
7 & Y & N & Y & Y \\
8 & Y & N & Y & N \\
9 & Y & Y & N & N \\
10 & N & Y & N & Y \\
11 & Y & Y & Y & N \\
\hline
\end{tabular}

The responses were noted after the GD by the students and were later handed over to the subject counselor. As it was seen, most of the students considered the presence of a text in the class to be somewhat unnecessary and this could be attributed to the examination pattern that was prevalent. Yet, why the inclusion of the text was not given a welcome move also had its bases in the peculiar situations that some of the student-subjects encountered-for example, owing to the high attention given to the attendance in the class and the compulsory presence for most of the time of the year, most of the students complained that reading the text per se and "between the lines" proved to be a waste of time when summaries and other critical materials were readily available. A good 15 students reported that commuting from their homes to the university took as long as 6 hours to and fro. The questionnaire did not incorporate such questions and parameters, but the reason the text was shunned by most of the students had its genesis in the typical pedagogical thrust that was adhered to.

The same questionnaire was administered to a group of around 49 students who had opted the "ODL" mode (Group "B") and the responses looked somewhat the same:

Table 3.

\begin{tabular}{lllll}
\hline Question no. & 15 students & 14 students & 14 students & 7 students \\
\hline 1 & Y & Y & N & Y \\
2 & Y & N & N & Y \\
3 & Y & Y & Y & N \\
4 & N & N & Y & N \\
5 & N & Y & Y & N \\
6 & Y & Y & Y & Y \\
7 & Y & N & Y & Y \\
8 & Y & N & Y & Y \\
9 & Y & Y & N & N \\
10 & N & Y & N & Y \\
11 & Y & Y & Y & N \\
\hline
\end{tabular}

Both the groups had performed well in the end-semester results and were more or less 'satisfied' with the way the task of teaching that was performed in the class. This included parameters as diverse as the teacher's way of explaining the text (and other texts that made up the syllabus), assignments given and checked, empathy for difficulties that students faced from poor families (like the debility to buy extra reference books as advised) from discerning teachers and the like. The last parameter was looked upon as a measure of the teacher's success as a good instructor by these students. 


\section{A Change in the Scenario}

It was noticed after the end-semester exams that were taken after every 6 months that the students performed better without the detailed study of texts per se and that considered the learning process within this paradigm to be conducive to their career. Thus, till now, positive responses from the success in term-end examinations led to the positive reinforcements of learner's inclination towards the course of study and both parameters were found to be a positive function of each other. In other words:

UST (Positive stimulus in term-end exams)- $\rightarrow$ URE (Response in form of greater attention to the course of study as a reward from the earlier parameter) $\rightarrow$ PRE (This trend is likely to continue as long as both the parameters are positively or directly related to each other)

The success in the examination and an overall score of around 54\% in Group A and 54.4\% in Group B led to positive learning mechanisms in the classroom in form of questions, queries and greater attendance. It seems that students had seen the course content, their own participatory process both in class as well as in home (during assignments and projects) and the term-end exams in a positive light. Yet, the central issue of the conspicuous neglect of longer texts remained.

After the second semester examinations were over, it was told to both the groups that there had been a slight change in the question pattern - from now onwards, there would be a compulsory section devoted to extracts from texts that were provided for detailed study in the syllabus but had hitherto been relegated to an optional section in the question paper. So, it was reported that from now onwards, a total 30 marks would be allotted for questions from abstracts form texts, whether in the syllabus (as in Group A), or used as an addendum (as in Group B). The students in both the groups were asked to discuss this in a GD and questionnaires were used to record their responses again:

The responses of students when attempting a textual question has become a must

1. Do you feel that a question from the text would be easy to attempt? Y/N

2. Do you feel that a textual question would fetch more marks?

$\mathrm{Y} / \mathrm{N}$

3. Do you feel that this change was needed? $\quad \mathrm{Y} / \mathrm{N}$

4. Will this change adversely affect your performance in the tests? $\mathrm{Y} / \mathrm{N}$

5. Should textual questions be done away with? Y/N

Sheet 2 .

A GD revealed (in both groups) that students were wary of attempting questions from texts and that they provided lesser 'incentives' in providing opportunities for fetching more marks than in case of 20 objective questions in Group A and 30 in B. Moreover, the answer to question no. 3 was an invariable "N" or "No" in both the groups, while over $80 \%$ students responded with a "Y" to question no. 4 in Group A and an overwhelming 94\% in Group B.

The term-end examinations showed the following results: more than $47 \%$ students scored less than $45 \%$ of marks due to the inclusion of compulsory textual question in Group A, while 55\% of students in Group B scored less than $45 \%$ marks as opposed to the previous percentile in both the cases when compulsory textual questions were introduced. Since the study has shown with recourse to the theory of operant conditioning, how positive outcomes in exams (stimulus) led to positive learning outcomes in the classroom, this change in the scenario led to a sort of distrust and askance in students, especially in Group B as regards the course they were enrolled in and the career opportunities associated with it once they enter job market. (Note 3)

\section{Findings/Conclusion}

The ODL courses in India in literature classes often do away with longer texts related to canonical as well as noncanonical authors, their detailed discussion during PCP programs (Note 4), and tend to incorporate only smaller texts related to poetry and other occasional pieces, but the learning outcomes when it comes to this inclusion/noninclusion of texts in both regular as well as in ODL courses yielded some fascinating results. That texts were not often adhered to by learners is what became the nodal point of analysis, coupled with the fact that this nonadherence was seen to be a rising trend amongst students in the Indian ODL modes of study. What then can be understood from the study is that learners often look at longer texts with askance and even internally debate their utility and have an ambivalent attitude towards them. In regular mode of study where the study of texts and reading between the lines is often encouraged, this study brought this fact into focus that irrespective of the mode of study, 
learners have a tendency to avoid the study of texts per se and tend to focus on notes, etc. than the full appreciation of the same. This study shows how learners were more attuned towards exam results and that the exam pattern and their success determined how positive would be learning outcomes in the class that was directly related to positive stimulus received via examinations and the further propensity to believe that there were positive influences at work in a classroom.

\section{Acknowledgements}

The author received no funding whatsoever while conducting this study and relied on his own experiences of being a teacher both in the ODL as well as in the regular modes of study in eastern India. However, the author is indebted to previous research and literature review that he has drawn upon while citing sources.

\section{References}

Ahmed, S. (2007). Job Creation and Poverty Reduction in India: Towards Rapid and Sustained Growth. New Delhi, Sage India.

Dzakiria, H. (2012). Illumination the importance of learning interaction to ODL success. European Journal of Open, Distance and E- Learning, pp. 1-9. Retrieved from https://files.eric.ed.gov/fulltext/EJ992489.pdf

Mnyanyi, B. F., \& Tolly, S. A. M. (2009). Open and Distance Learning in Developing Countries: The Past, The Present and The Future. M-2009. Retrieved from https://www.ou.nl/Docs/Campagnes/ICDE2009/Papers/Final_paper_280Mnyanyi.pdf

Mohanachandran, D. K., \& Subramanium, S. R. (2013). Work and Schooling Challenges of ODL: Case Study. Research Journal of Social Science and Management, 2(10), 198-207. Retrieved from https://www.researchgate.net/publication/259312208_WORK_AND_SCHOOLING_CHALLENGES_OF_ OPEN_DISTANCE_LEARNING_CASE_STUDY

Musingafi, M., et al. (2015). Challenges for ODL Students: Experiences from Students of the Zimbabwe Open University. Journal of Education and Practice, 6(18), 59-66. Retrieved from https://files.eric.ed.gov/fulltext/EJ1079750.pdf

Narula, M., \& Pankaj, N. (2013). Relationship Between Student's Performance and Class Attendance in a Programming Language Subject in a Computer Course. International Journal of Computer Science and Mobile Computing, 2(8), 206-10. Retrieved from https://www.ijcsmc.com/docs/papers/August2013/V2I8201318.pdf

Olivier, B. H. (2016). The Impact of Contact Sessions and Distributed Forums on the Academic Performance of ODL Students. International Review of Research in Open and Distributed Learning, 17(6), 75-88. https://doi.org/10.19173/irrodl.v17i6.2493

Thompson, T. (2007). Relations Among Functional Systems in Behavioral Analysis. Journal of the Experimental Analysis of Behaviour, 87(3), 423-440. https://doi.org/10.1901/jeab.2007.21-06

Wolman, B. D. (1981). Contemporary Systems and Theories in Psychology. Berlin: Springer. Reprinted in 2012. https://doi.org/10.1007/978-1-4684-3821-5_15

\section{Notes}

Note 1. The foreword to SIM /Study Materials of NOSU (Netaji Subhas Open University) in Kolkata, India emphasizes on the fundamental fact that any learner with a genuine thirst for learning may be enrolled in its courses of study, as the ODL mode in general does not believe in any "artificial differentiation" while choosing students.

Note 2. This study was basically conducted for a group of students in economics, but can embrace all learners in the Indian scenario.

Note 3. It seems that the various parameters of the 'soundness' of a course of study as believed by learners were those that gave the necessary opportunities that were needed to enter the job market in India that depended on cutoff marks in some sectors like Defence (non-first classers are generally not allowed to apply) and not necessarily on the life and work skills that some selected programs in the ODL mode had in store for them. Hence, the better the score, the better the chances of survival. For a comprehensive account of the relationship between poverty, growth and the job sector in India, see Ahmed.

Note 4. Some of the reasons cited were the paucity of time vis-à-vis the need to finish one topic per class owing to the schedule of the Personal Contact Programme (PCP) as per the directives of the ODL curriculum. This often 
results in the scant discussion of the subject matter and the entire stuff is often left to the students. However, it is also expected that students would 'make up' the same at home as they have sufficient time for self-study, as PCPs are often deemed non-compulsory.

\section{Copyrights}

Copyright for this article is retained by the author(s), with first publication rights granted to the journal.

This is an open-access article distributed under the terms and conditions of the Creative Commons Attribution license (http://creativecommons.org/licenses/by/4.0/). 